Fernandez, A. V. and A. Køster. (Forthcoming 2019). "On the Subject Matter of Phenomenological Psychopathology." In Stanghellini, G., M. Broome, A. V. Fernandez, P. Fusar-Poli, A. Raballo, and R. Rosfort (Eds.), The Oxford Handbook of Phenomenological Psychopathology. Oxford University Press.

This is the pre-copyedited version of the chapter. An online version will be made available at Oxford Handbooks Online prior to print publication. Please quote from published version.

\title{
On the Subject Matter of Phenomenological Psychopathology
}

\author{
Anthony Vincent Fernandez and Allan Køster
}

\begin{abstract}
"On the Subject Matter of Phenomenological Psychopathology" provides a framework for the phenomenological study of mental disorders. The framework relies on a distinction between (ontological) existentials and (ontic) modes. Existentials are the categorial structures of human existence, such as intentionality, temporality, selfhood, and affective situatedness. Modes are the particular, concrete phenomena that belong to these categorial structures, with each existential having its own set of modes. In the first section, we articulate this distinction by drawing primarily on the work of Martin Heidegger - especially his study of the ontological structure of affective situatedness (Befindlichkeit) and its particular, ontic modes, which he calls moods (Stimmungen). In the second section, we draw on a study of grief to demonstrate how this framework can be used when conducting phenomenological interviews and analyses. In the concluding section, we explain how this framework can be guide phenomenological studies across a broad range of existential structures.
\end{abstract}

Keywords: grief; Heidegger; phenomenology; psychopathology; structure; subject matter 


\section{Introduction}

Phenomenology is typically characterized as the study of human experience. But, in its philosophical sense, it's more than the study of "what it's like" or "what it feels like" to have experiences. It's not equivalent to a qualitative study or a narrative self-report - although it might draw on evidence from such studies and reports. What, then, is phenomenology in its philosophical sense? Philosophical phenomenology is often characterized as a study of the "structure" of human consciousness, experience, or existence (e.g., Luft \& Overgaard 2011; Smith 2013; Zahavi 2012). However, in much of the contemporary phenomenological literature, this key notion of "structure" is left undefined. And, when it is defined, it's typically given only a vague or cursory characterization: "structure" refers to the form or shape, rather than the content, of experience. This gets us a bit closer to what phenomenologists mean by "structure," but contemporary phenomenologists deserve something more definite. They deserve a well-articulated framework for conducting their phenomenological investigations.

Psychopathology is, by contrast, an interdisciplinary research program that aims to understand and explain the nature of mental disorders (Jaspers 1997). Today, psychopathology is largely concerned with providing explanations of mental disordersidentifying, for example, the genetic, neurobiological, and social factors that contribute to psychopathological conditions. However, psychopathology also requires that we understand, not just explain, the conditions in question. Phenomenology, as a descriptive study of lived experience, is one of the major methodological approaches for achieving this kind of understanding (Jaspers 1968).

But when we turn to the phenomenological study of psychopathology, the question of phenomenology's subject matter becomes even more complex. To properly comprehend the psychopathological condition in question, the phenomenologist must articulate the 
experiential or existential structure of this condition — not just of experience or existence in general. And this requires that the phenomenologist specify how the general structure has been altered or disturbed in this particular case. Ludwig Binswanger, one of the first psychiatrists to apply phenomenology to the study of psychopathology, says, "in the mental diseases we face modifications of the fundamental or essential structure and of the structural links of being-in-the-world as transcendence. It is one of the tasks of psychiatry to investigate and establish these variations in a scientifically exact way" (Binswanger 1958: 194). If, however, we lack a clear account of what we mean by "structure," then the difficulty of doing applied phenomenology is only compounded in its application to psychopathology. As with contemporary phenomenologists in general, phenomenological psychopathologists have not adequately defined this key term. They also use it as a synonym for "form," "shape," and so on (see, e.g., Parnas \& Zahavi 2002).

In light of this shortcoming in the phenomenological literature, we here provide a detailed account of the phenomenological notion of "structure." We argue that there are at least two distinct kinds or layers of structure that are not properly disambiguated in the literature —what we call "existentials" and "modes." Once we properly distinguished them, we'll have a clearer sense of what it means to articulate both the structure of human experience in general and how experience can be altered or disturbed in particular cases. In the first section, we articulate this distinction with definitions and examples. ${ }^{1}$ In the second section, we demonstrate how the distinction between existentials and modes can guide our study of psychopathological and psychologically distressing conditions. Our intention is to provide a means of framing phenomenological investigations and clearly communicating the

\footnotetext{
${ }^{1}$ The framework that we provide here is based on work that both authors developed separately (in some cases with other co-authors). See, for example, (Fernandez 2017; Fernandez \& Stanghellini forthcoming; Fernandez \& Wieten 2015; Køster 2017a, 2017b; Køster \& Winther-Lindqvist 2018).
} 
results of phenomenological studies, which will, in turn, facilitate critical and complementary dialogue - ultimately driving the field of phenomenological psychopathology forward. ${ }^{2}$

\section{The Layers of Phenomenological Research}

In this section, we outline the two layers of phenomenological research: existentials and modes. This distinction has foundations in the classical phenomenological texts and is implicit in much of the contemporary phenomenological literature - not only in the study of psychopathology, but also in studies of race, gender, culture, and so on. In this respect, we don't mean to impose an external framework on the field of applied phenomenology. Rather, we provide an explicit articulation of a framework that stands in the background of many contemporary phenomenological studies.

The first layer of phenomenological research is "existentials." This term is a Heideggerian coinage, but it can be applied across a variety of phenomenological approaches. As we use it, the term is a rough synonym for what other phenomenologists call "transcendental," “essential," or “ontological” structures of experience. ${ }^{3}$

In Being and Time, Heidegger analyzes the structures that are constitutive of human experience and existence. In this respect, he articulates "not just any accidental structures, but essential ones which, in every kind of Being that factical Dasein may possess, persist as determinative for the character of its Being" (Heidegger 1962: 38). By "factical Dasein," he simply refers to a concrete, particular human existence. He aims, therefore, to articulate those

\footnotetext{
${ }^{2}$ While we offer an account of the subject matter of phenomenological psychopathology, we do not intend this to be an account of the subject matter of phenomenological psychiatry more broadly. We take psychopathology to be one component of the broader field of psychiatry, which also includes psychotherapy, psychopharmacology, and so on. In light of this, we acknowledge that there are other phenomenological approaches to psychiatry, such as phenomenological approaches to psychotherapy, that may exceed the boundaries of the framework that we provide here.

${ }^{3}$ We prefer the term "existentials" because it does not require the use of the term "structure." Since much of the ambiguity and vagueness in contemporary phenomenological research stems from an overuse of the term "structure," we prefer to use a label that does not employ this term.
} 
structural features that hold for human existence in general, applying across all particular cases. These structural features are what we call "existentials."

But what are existentials? A simple way to conceptualize existentials is to think of them as categories. ${ }^{4}$ They are not, however, categories of objects within the world, such as the categories 'tree', 'bicycle', or 'nation'. As Heidegger says, "Existentials and categories are the two basic possibilities for characters of Being. The entities which correspond to them require different kinds of primary interrogation respectively: any entity is either a " $w h o$ " (existence) or a "what" (presence-at-hand in the broadest sense)" (Heidegger 1962: 71; translation modified). When we turn our attention toward the experiencing subject, we no longer concern ourselves with categories of objects within the world. Instead, we concern ourselves with the categorial structures of human experience and existence, such as intentionality, temporality, understanding, selfhood, and affective situatedness, among others. All instances of human existence include these basic structural features. That is, all experience is intentional (i.e., directed toward some object or state of affairs), has a temporal flow, is affectively situated, and so on.

Existentials, like categories, fundamentally differ from the particular phenomena that they encompass. There are, for instance, a variety of ways in which one might be intentionally oriented toward one's environment, various styles of temporal flow, and diverse affective states. However, when we study the existentials themselves, we don't concern ourselves with the particular ways in which these existentials manifest. We concern ourselves with the existential, or categorial structure, itself. We aim, for instance, to articulate the basic, defining features that hold for any instance of intentionality, temporality, affectivity, and so

\footnotetext{
${ }^{4}$ This characterization of existentials is, admittedly, contentious. When Heidegger introduces his notion of existentials in Being and Time, he famously says that they "are to be sharply distinguished from what we call 'categories' — characteristics of Being for entities whose character is not that of Dasein" (Heidegger $1962 \mathrm{p}$. 70). However, he here refers to "categories" in a narrow metaphysical sense (e.g., Aristotle's metaphysical categories). Throughout his early lectures, Heidegger used the term "categorial" [kategorial] to characterize to the very structures that he later rebranded as "existentials" in Being and Time (see, e.g., Heidegger 2008).
} 
on. In this respect, the study of existentials is ontological-it's concerned with what it means to be this or that kind of being. As phenomenologists, we sometimes ask big questions, such as "What does it mean to be human?" But we also ask more specific questions, such as "What is intentionality?" or "What is temporality?" When we answer these kinds of ontological questions, we typically do so by articulating a category. To properly understand the being of some phenomenon, i.e., to clarify what it $i s$, we have to properly categorize it. We can clarify this approach with the everyday categories noted above. If I ask, for instance, "What is a bicycle?" I'm not asking you to tell me anything specific about this bicycle. I'm asking you to articulate the category 'bicycle'-i.e., the defining features that make something a bicycle. Once I have a sense of these defining features, then I'm in a position to distinguish among those entities that do, or do not, fall into the category 'bicycle'.

If the study of an existential is like the study of a category, then what does this kind of study look like in practice? We can illustrate the study of an existential with a more detailed analysis of affective situatedness $[$ Befindlichkeit $] .{ }^{5}$ We rely on this as our primary example of an existential for three reasons: First, Heidegger describes the existential of affective situatedness in considerable detail. Second, he clearly distinguishes affective situatedness (i.e., the existential) from particular moods (i.e., the modes of this existential) which will help us clarify the general relationship between existentials and modes. Third, affective situatedness is a central topic in phenomenological psychopathology_especially in the study of affective disorders - which will allow us to easily link this initial sketch of existentials with our discussion of how existentials are studied in phenomenological psychopathology.

\footnotetext{
${ }^{5}$ Heidegger's neologism, Befindlichkeit, is remarkably difficult to translate. No English term is an exact correlate. In the Macquarrie and Robinson translation, it is translated as "state-of-mind," but this translation is rarely used in the English-language scholarship. Alternative translations include "affectedness," "disposedness," "sofindingness," "attunement," and "situatedness," among others. In this chapter, we typically use the term "affective situatedness," but also refer to "attunement" when this captures the distinctive aspect of Befindlichkeit that we're trying to express.
} 
As an existential, affective situatedness refers to the fact that we always find ourselves in the world through a particular affective attunement—what Heidegger calls a "mood" (Stimmung). Even our everyday "pallid, evenly balanced lack of mood" is still a mood - it's a way of finding ourselves affectively attuned to and situated in the world (Heidegger 1962: 173). And affective situatedness, like all existentials, has “essential characteristics" - that is, a set of defining features that hold for any of the phenomena that belong to this ontological category. Heidegger argues that there are three essential characteristics of affective situatedness: It (1) discloses our thrownness, (2) discloses beingin-the-world as a whole, and (3) lets us encounter the world as meaningful.

(1) By thrownness, Heidegger refers to the experience of what he calls "the naked that it is and has to be". That is, the precarious experience that we don't choose our existence, but always already find ourselves delivered over to and having to exist in a pre-structured historical world. In this sense, Heidegger argues, existence is disclosed to us through affective situatedness as a burden that we have to carry, and this burdensomeness is made apparent by our mood.

(2) When Heidegger says that moods disclose being-in-the-world as a whole, he means that moods aren't internal mental states that simply color an objective world. Rather, as Heidegger says, “[a] mood assails us. It comes neither from 'outside' nor from ‘inside'...” (Heidegger 1962: 176). Our moods disclose the world, others, and ourselves simultaneously.

(3) When Heidegger says that moods allow us to encounter the world as meaningful, he means that in order to find anything meaningful at all, it must have some kind of affective pull on us. Which kind of affective pull something has will depend on the mood we happen to find ourselves in. But things can have an affective pull only because we're attuned through some mood or other. As Heidegger says, we 
must be attuned to the world through a mood to "be 'touched' by anything or 'have a sense for' something” (Heidegger 1962: 177)

In addition to having essential characteristics, each existential can be analyzed by focusing on "general structures." In affective situatedness, Heidegger illustrates this through the example of a concrete mood: fear. ${ }^{6}$ He says that the three structural elements of fear are "(1) that in the face of which we fear, (2) fearing, and (3) that about which we fear" (Heidegger 1962 p. 179). Consider, for example, the experience of coming across a large bear while hiking in the woods. In this case, (1) I am fearful in the face of the bear (i.e., the bear is fearsome); (2) I experience the qualitative feeling of fear; and (3) I am fearful about my own life or the possibility of coming to bodily harm. In like manner, I might be joyful upon receiving a letter of acceptance to my top choice university. In this case, (1) I am joyful in the face of my acceptance; (2) I experience the qualitative feeling of joy; and (3) I am joyful about my future life as a university student or the future prospects for my career. These three elements are not a sequence of events, but a simultaneous structural whole. They constitute the general structure of this existential — and, thus, the general structure of any mood or mode of affective attunement. As Heidegger says, "These possible ways of looking at fear are not accidental; they belong together. With them the general structure of affective situatedness comes to the fore" (Heidegger 1962: 179).

It is, however, important to clarify that, on Heidegger's account, what it means for a mood to be experienced "in the face of" something is a rather permissive criterion. Our mood need not be experienced in the face of an object within the world. As Heidegger clarifies in

\footnotetext{
${ }^{6}$ It may seem strange to refer to fear as a mood rather than an emotion. Moods are often characterized as pervasive background states without a clear object. Emotions, on the other hand, are affective states that are directed toward, or are about, an object. Fear would therefore fall into the category of emotion rather than mood. However, Heidegger's use of the term Stimmung, which is translated as "mood," doesn't distinguish between affective states that have, or do not have, an object. While we follow Heidegger's broad use of the term here, his failure to clearly draw a distinction between intentional and non-intentional affective states is one of the motivations behind our move toward Ratcliffe's concept of existential feelings.
} 
both Being and Time and The Fundamental Concepts of Metaphysics (2001), a mood may also be experienced in the face of an event (e.g., being bored at a dinner party) or even in the face of the world as a whole. Moods that take this last form are what Heidegger calls "ground moods" [Grundstimmungen]. These are pervasive background feelings that determine the kind of sense and meaning that we are capable of experiencing. Heidegger's concept of ground moods largely overlaps with Matthew Ratcliffe's concept of "existential feelings" (Ratcliffe 2008). In the following section, we'll demonstrate how one might focus on ground mood, or existential feelings, by providing a brief analysis of grief.

To summarize, in much the same way that we distinguish between categories of things — such as 'trees', 'bicycles', or 'nations' — and the particular things that belong to these categories, we can distinguish between the existential itself and the modes that belong to the existential. The modes of situatedness are moods, or concrete affective attunements, but we can also speak of modes of selfhood, temporality, spatiality, and so on. But we can also describe how phenomenologists study particular modes in more detail.

\section{Application in Phenomenological Psychopathology}

Before we demonstrate how to investigate existentials and modes in contemporary applied phenomenology, it will be helpful to distinguish two ways that phenomenologists study modes, whether they be modes of situatedness, temporality, selfhood, or what have you. First, phenomenologists may study a mode with the aim of understanding it with respect to its generality - that is, with the aim of articulating the essential characteristics or the general structure of the existential that this mode belongs to. Second, phenomenologists may study a mode with respect to its particularity — that is, with the aim of understanding the character of this specific mode. The former investigation is ontological (i.e., a study of the being or essence of a kind of phenomenon); the latter investigation is ontic (i.e., a study of a 
particular, concrete phenomenon). ${ }^{7}$ Heidegger's project is, first and foremost, ontological—it is concerned with the basic structures of human existence in general. By contrast, most studies in applied phenomenology —including phenomenological psychopathology — are ontic insofar as they're concerned with describing particular modes, or ways, of being in the world. However, we argue that these studies can also feed back into the ontological project, helping us delineate and define the existentials themselves. In the following two subsections, we briefly demonstrate how contemporary applied studies can feed back into and clarify our ontological account of the structure of human existence - then, using the example of grief, we provide a more detailed example of the kind of analysis phenomenologists can produce through ontic studies of particular modes.

\subsection{Refining our Ontological Accounts of Existentials}

If we take existentials as the necessary, invariant structures of human existence and modes as their contingent, variable manifestations, then how should phenomenological psychopathologists investigate existentials? One answer is that the study of existentials simply isn't the business of those doing phenomenological psychopathology—or any form of applied phenomenology, for that matter. Existentials are investigated by the more philosophically minded, pure phenomenologists, who concern themselves with the structure of human existence in general. This position stems from the view that phenomenological psychopathology and other fields of applied phenomenology are merely applied. That is, applied phenomenology is merely the ontic study of particular forms of human existence and, therefore, has nothing to say about the structure of existence in general - it simply assumes

\footnotetext{
${ }^{7}$ The distinction between the ontological and the ontic is Heideggerian. However, it's roughly synonymous with the distinction between the transcendental and the empirical, or mundane, which we find in the work of Edmund Husserl and Maurice Merleau-Ponty, among others.
} 
this general structure, which has already been identified and articulated by the classical phenomenologists.

We, however, take a more collaborative, mutually informative view of the relationship between applied phenomenology and what may be called "pure phenomenology" (by Husserl) or "fundamental ontology" (by Heidegger). The latter labels refer to the study of the structure of human experience and existence in general — not its particular manifestations across the human population. ${ }^{8}$ If, however, we examine how the classical phenomenologists arrived at their accounts of the essential characteristics and general structure of existentials, we find that they do so by investigating a particular, ontic mode of the existential in question. This approach is similar to Husserl's method of variation, in which you vary a particular phenomenon (real or imagined) to identify the invariant features of this kind of phenomenon. Heidegger does not take over this explicit method, but there's a similar approach in the background of his study of existentials.

Regardless of the particularities of the method, it's clear that we don't have immediate insight into the essential characteristics and general structures of existentials. We discover the characteristics and structure through the study of particular modes. And, as with any empirically informed study, we may misidentify the characteristics and structure of the category that the phenomenon belongs to. If our sample of phenomena is too small, we're simply not in a good position to know what these features are.

The same kind of issue may occur when defining a category of objects within the world. If I tried to identify the defining features of, say, teacups, I might determine that having a handle is one of these defining features. But what if I'm introduced to tea-drinking traditions in East Asia, where it's common for teacups to lack a handle? Once I'm presented

\footnotetext{
${ }^{8}$ In this chapter, our account of the subject matter of phenomenological psychopathology assumes an invariant existential structure, or set of existentials, exhibited by all human subjects. However, we think that the invariance of existentials is an open question deserving of further discussion and debate. For an account of the possibility of existential or ontological contingency, see (Fernandez 2015, 2018)
} 
with this case, I seem to have two options: I can decide to remove handles as a defining feature of teacups, thus broadening my category; or, alternatively, I may decide that the teacup-like object used in East Asia just doesn't count as a teacup_it's some other kind of object.

There are at least two lessons to be learned from this example: First, if our initial sample of phenomena is too small, we have a greater risk of misidentifying the defining features of the category in question. Second, whether we decide to modify our current category or establish a new one is often a pragmatic issue. If we consider the teacup example, there don't seem to be any a priori criteria that we can use to decide one way or the other in this case. Similar issues arise in the phenomenological study of existentials. We shouldn't assume that the classical phenomenologists got everything right. But we also shouldn't assume that there's only one right way to carve up and characterize the various existentials. Sometimes we have good reason to delimit the domain of experiential phenomena in a new way - and this doesn't necessarily imply that the previous delimitation was wrong.

For an example of this kind of redescription of ontological structures in phenomenological psychopathology, we can turn to Matthew Ratcliffe's recent work on existential feelings (Ratcliffe 2008). ${ }^{9}$ Ratcliffe explicitly develops his concept of existential feelings from Heidegger's notion of affective situatedness, modifying the concept in light of his own aims. One of Heidegger's significant contributions was to outline the very worldopening function of affectivity. However, he doesn't provide a robust taxonomy of affective phenomena. Heidegger's notion of affective situatedness does not, for instance, adequately distinguish between intentional and non-intentional affective phenomena-i.e., those that have an object (such as emotions) and those that do not (such as moods). As we noted above,

\footnotetext{
${ }^{9}$ We here provide only a brief account of Ratcliffe's concept of existential feelings. For further reading, see Ratcliffe $(2009,2013)$.
} 
when Heidegger says that moods are experienced in the face of something, he means this in a broad sense. Some moods may have an intentional object within the world, but others are experienced in the face of an event or in the face of the world as a whole.

Ratcliffe, by contrast, more clearly delimits his concept of existential feelings as a separate phenomenological category, or what we call an existential. Existential feelings refer specifically to background feelings that are pre-intentional-i.e., feelings that do not have an object, but provide an affective background within which we have other intentional experiences, such as emotions or beliefs. Moreover, Ratcliffe stresses the bodily aspect of existential feelings, which is almost entirely missing from Heidegger's philosophy (see, e.g, Aho 2010). Existential feelings are specifically bodily feelings that determine "ways of finding ourselves in the world, existential backgrounds that shape all our experiences" (Ratcliffe 2008: 41). They are simultaneously feelings of ourselves and the world, and include a broad range of affective phenomena, such as feelings of familiarity, alienation, of being or not being at home in the world, of estrangement, and so on. By delimiting the existential in this way, Ratcliffe is able to zero in on more clearly defined aspect of experience, drawing fine-grained distinctions across its diverse experiential manifestations (Ratcliffe 2008: 53). In the following subsection, we follow Ratcliffe's refinement of Heidegger's notion of affective situatedness, focusing instead on a study of the more clearly delimited phenomena of existential feelings.

\subsection{Examples of Modal Alterations}

What kind of phenomenological insights might be generated when focusing specifically on modal variations in particular experiential states? In the following, we briefly illustrate this by providing excerpts taken from retrospective, phenomenological interviews conducted with persons who have suffered early parental bereavement. The research design included a total 
of 20 informants who lost a parent between the age of 5-18. They were systematically selected with a current age dispersion between 20-50 years old to more accurately identify potential lasting alterations. Each informant was interviewed a total of six hours. The interviews were phenomenological in the respect that they were (1) pre-structured by phenomenological insights, specifically with attention to the existential-mode distinction; (2) carried out through a phenomenological-hermeneutic attitude; and (3) subsequently analyzed with the extensive use of phenomenological concepts. Much more could be said about the details of this process, but for the current purpose it will have to suffice to add that although the interviews were conducted through an open and hermeneutic attitude, the specific lines of questioning were guided by pre-established phenomenological insights on various experiential structures, or existentials. For example, part of a two-hour interview devoted to mapping the affective dimension of early parental bereavement was specifically structured to solicit descriptions of potential alterations in existential feelings. This style of questioning not only assumes such an aspect of experience, but is also sensitive to the difficulty of verbalizing or narrating this aspect of experience. ${ }^{10}$ To solicit rich descriptions of existential feelings, the interviewer needs to allow for, and perhaps even encourage, the extensive use of metaphors and fuzzy concepts that require greater levels of time, patience, and assistance to adequately articulate. This is, moreover, a standard element of qualitative interview techniques.

Our aim here is not to provide an exhaustive analysis of the effects of bereavement. It is, rather, to demonstrate the utility of the distinction between existentials and modes when applied to specific research contexts. We therefore confine ourselves to a few interview excerpts that are demonstrative of modal alterations in affective attunement. Hence, these

\footnotetext{
${ }^{10}$ For a detailed account on the relation between embodied experiences and narrative see Køster (2017c).
} 
should not be read as an attempt to give an exhaustive account of the heterogeneous affective dimension of grief $^{11}$.

It should also be noted that, although it has long been accepted in psychology and psychiatry that grief can become pathological, it is not until recent years that systematic discussions and research has been aimed at defining some grief responses as pathological in their own right — that is, as a nosologically distinct category. However, since the specific diagnostic criteria are still debated, we do not confine our phenomenological analysis to modal alterations of pathological grief — since the distinctly pathological form of grief has not been clearly identified. However, this also provides us with an opportunity to demonstrate how phenomenology can contribute to the literature on pathological grief and the process of identifying and characterizing pathological conditions. As we show, phenomenology is an especially powerful tool for distinguishing among subtle experiential alterations and disturbances. Such distinctions can provide psychiatrists with a map of the terrain, which they can use to better distinguishing among those conditions they want to class as pathological, non-pathological, or subthreshold.

The three excerpts exhibited below all display aspects of a particular tendency in the modal alterations of affective attunement that we might characterize as world-distancing, which is a particular way in which the world is affectively disclosed. This tendency was consistent across most informants. However, informants exhibited significant scalar differentiations in intensity and frequency. Most informants considered these alterations a new experiential disposition, in the sense that it was not there before bereavement, but has become a recurring experience after bereavement. In multiple cases, it was even considered an experiential constant, i.e., as an aspect of experience that was more or less always there. ${ }^{12}$

\footnotetext{
${ }^{11}$ A systematic phenomenological analysis of the modal alteration in affective situatedness following early parental bereavement can be found in (Køster forthcoming).

12 This, of course, would have to be validated on a much larger sample, which calls for quantitative research methodologies. Migrating the phenomenological insights into operational scales for measuring this on a larger
} 
Let's start with a passage from a 49 year old man who lost his mother at the age of 12 . He describes the emergence of a world distancing affective attunement in the following way:

'To me this feeling of distancing is similar to a train running. It's my life, and I am on the platform watching the train run by. You know, the best metaphor is perhaps looking at a party and, just for a few seconds, having stepped out into the garden and watching the party from afar. You know there are a lot of people, and I have a relation to all of them. Everybody is having fun, but I have stepped outside. I observe it all. And it is perhaps really that observing stance from the outside that best describes the changed feeling, it's a kind of bubbling up. It's a different feeling of being in a blur, like things are a bit out of focus because I experience it from afar. When thinking of this state all I can think of is calmness. There is no noise. Perhaps I can describe it by saying there is no sound. And this kind of displacement was not only an initial feeling. It is a recurring feeling, one that has become a property of my way of being...In this sense the world has become much more twodimensional. It has no depth, the world is no longer as nuanced, I think. There are not as many layers, I think, or that's what I am left with when I say that it's soft and calm. You know, when you observe from a distance, you don't get all the details, some of the senses don't exists, as for instance the sense of smell, because you are watching things from afar'.

As already noted, a key element in Heidegger's notion of affective situatedness and Ratcliffe's existential feelings is that they shape how we find ourselves affectively present and situated in the world - that is, our affective attunements open, or disclose, the world in a particular way. How is this aspect of experience altered in this excerpt? First, it's important 
that the informant himself refers to distancing as a feeling. It is a feeling of 'bubbling up', of 'being in a blur', a feeling that alters the way the world manifests in the sense that it is now 'more two-dimensional', without color and lacking in sensory qualities, partially because it is observed from afar. Importantly, this altered state of being-in-the-world should not be seen as a simple deprivation. It also provides a sense of calmness. Elsewhere, the informant refers to what we've called the affective attunement of world-distancing as 'a protective airbag'. The attunement certainly has distressing and debilitating features, but the informant himself experiences his attunement as a kind of defensive stance, protecting him from the harsh reality of his loss.

The contours of this description are echoed by a 33 year old woman who lost her father at the age of 16 . However, she adds an important temporal modality to this modal change in affective attunement:

'I consider it, this feeling of distancing, as almost a metaphysical feeling. I am in my body but the world is cloudy. I am confined to my own shell, and time has stopped; everybody else is continuing their lives, but I am stuck in stillness. It's a kind a vacuum, where time feels abstract. It's a feeling of being fundamentally alone in the world... One might perhaps also say that I feel like I am continuously caught behind a glass plate and watching the world and other people through this screen'.

Again, she explicitly refers to the sense of distancing as a feeling, in this case a 'metaphysical feeling', that describes a particular way of finding oneself in the world. As emphasized, however, she adds a clear temporal dimension to this experience: distancing is a feeling of 
being 'stuck in stillness' because 'time has stopped', separated from the temporal flow of the world. ${ }^{13}$

A 28 year old woman who lost her mother at age 10 complements these descriptions by elaborating on the social implications of world-distancing as a particular mode of attunement:

'I think it is a bit like being in a bubble; well, it's a feeling of being in a bubble and when somebody is talking to you it just becomes this myriad of words, this stream of fuzzy talk, because it is difficult to localize it, because you are caught in your own bubble. One keeps thinking that this is what is happening, and then that only makes it worse. Often I feel, though, that I am able to tune-in on the conversation, but it is really hard to remain present. I hear the words, but I can't be fully present, so I end up just saying hmmm, and platitudes like "I know that". Sometimes I feel like shaking my head a bit, to see if it disappears, but it's really difficult. It's a bit like having the hiccups and trying to think it away-it does not work. I start thinking that they notice that, they can tell you are not listening. It's really unpleasant. I get this feeling very often, almost daily, since my mum passed. At least it feels like that'.

In this passage, she emphasizes how the feeling of distance impacts the capacity to follow the rhythm and resonance of social interaction. She feels cut off from the interaction as a result of the preceding affective state of distance.

Taken together, these excerpts draw out basic contours of modal alterations of affective attunement and affective situatedness that are characteristic of suffering early parental bereavement - even years or decades after the loss. Our focus here has been on

\footnotetext{
${ }^{13}$ Thomas Fuchs has argued that depressive disorders often involve temporal and intersubjective desynchronization (Fuchs 2001, 2013). Since we find a similar phenomenon in cases of grief, it may be worth conducting a comparative study of grief and depression to determine whether there are key differences in the kind of desynchronization experienced by persons in the two groups.
} 
world-distancing as an existential feeling, or mode of affective situatedness. The informants report a peculiar way of finding themselves affectively attuned to the world in which the world seems difficult to reach, as if reality is somehow separate from them, on the other side of a barrier. They report feeling alone, regardless of the concrete social situation they currently find themselves in. Moreover, some informants suggest that this disclosure of the world as distant or hard to reach also comes with a sense of softness or calmness. The feeling of being alone and distant makes it difficult to connect with others, but it also protects one of the harsh realities of everyday life.

The specific analyses we've offered here are brief, since our aim is not to provide a detailed analysis of grief, but to provide an illustration of how to conduct a phenomenological study. We can, however, provide a more detailed account of how further analyses of these kinds of interviews might proceed. The essential characteristics and general structure of affective situatedness, or existential feelings, helps us initially identify this specific kind of phenomenon in the informants' reports. But we should also return to these characteristics and structure when performing our analyses. Heidegger, for example, says that essential characteristic of affective situatedness is that it shapes the meaningfulness of the world, or the kind of sense and meaning that we can find within the world. And Ratcliffe points out that existential feelings determine our sense of reality. In light of these characteristics, we might analyze the informants' reports with the explicit aim of articulating not only which mode of attunement they find themselves in, but also how, exactly, this attunement shapes the meaningfulness of their world and their sense of reality. By describing these characteristics in more detail, we're able to articulate what's distinctive, or perhaps even unique, about the affective dimension of grief.

However, it's also important to clarify that despite the consistency of the affective dimension of grief illustrated in these excerpts, we are not suggesting that these alterations 
constitute a strict invariant structure of the affective dimension of grief and bereavement. What first-person descriptions, such as these, may produce are rather illustrations of modal variations in affective attunement. These variations express tendencies, in the sense that they are typical or characteristic of early parental bereavement, but may not manifest in all cases. This points to a significant difference in the type of knowledge phenomenological analysis can be expected to provide when moving from the ontological focus of philosophical phenomenology to the level of specific empirical cases. As any researcher with experience in empirical case-studies will be able to recognize, real life cases are always ontogenetically specific and context-dependent. Therefore, we should not expect to identify something like an essence of grief, or even an essence of the affective dimension of grief. At the ontological level, we might identify an essence of affective situatedness, an essence of temporality, and so on. But, in our ontic, modal investigations, we may be able to identify only what is typical or characteristic of the experience in question. Modal alterations manifest in subtly different ways, which are often difficult to clearly distinguish. The boundaries of modal phenomena, including affective attunements, may often be blurry and ambiguous - not just because we haven't described them in enough detail, but because they are, by their very nature, blurry and ambiguous. In this case, at least, we take ourselves to have articulated certain generalities or tendencies that are typical of, but not necessarily essential to, the experience of early parental bereavement.

\section{Conclusion}

In this chapter, we've outlined the subject matter of phenomenological psychopathology with the aim of providing a clear, easily applicable framework for conducting studies and reporting the results of one's research. To illustrate this framework, we relied on Heidegger's notion of affective situatedness and Ratcliffe's notion of existential feelings. However, the 
framework that we've provided is meant to be applicable across the full range of existentials. In addition to affective situatedness, we might study modes of temporality, spatiality, selfhood, intentionality, and so on. To perform a concrete phenomenological study of these modes, one should begin by providing a clear account of the essential characteristics and general structure of the existential in question. Once this has been adequately articulated, then one can investigate the specific modal alterations of this existential in question, analyzing the particular ways in which is characteristics and structure manifest.

For example, to perform a similar phenomenological study of potential modal alternations in temporality following early parental bereavement, we would first need to provide a clear account of temporality's essential characteristics and general structure. Temporality has, for instance, a retentional-protentional structure: We retain what has just been experienced as just past and anticipate what is about to come, forming what may be called the specious present or extended now. Moreover, temporality includes the characteristic of conation, or striving, toward some future possibilities. And these possibilities are projected in light of who we already take ourselves to be. In light of this outline of the essential characteristics and general structure of temporality, one could develop a specific interview guide focusing on these aspects of temporality. Once the interviews have been conducted, they should be analyzed utilizing phenomenological concepts to uncover and clearly articulate tendencies and typical modal alterations.

By framing one's study in this way, one can easily compare the results of the study with other studies of modal alterations in the same existential, but across different kinds of conditions. One might, for instance, compare modal alterations in the temporality of grief with modal alterations in the temporality of depression to determine whether these experiences differ and, if so, how. This approach also allows researchers to investigate how modal alterations in one existential may complement modal alterations in another existential 
that occur in the same condition. One might, for instance, attempt to integrate studies of modal alterations in grief as they occur across the existentials of affectivity, temporality, and selfhood. Such an integration can provide a more complete, holistic account of the experience of grief.

Because many phenomenologists have developed their own distinctive set of concepts and style of phenomenological description, it is often difficult to compare the results of phenomenological studies. This hinders our ability to engage in critical and complementary dialogue, which is key to the continued success of phenomenological psychopathology. We hope that our proposed framework will provide an effective foundation for such dialogue, ultimately driving the discipline forward.

\section{References}

Aho, K. A. (2010). Heidegger's Neglect of the Body. Albany: SUNY Press.

Binswanger, L. (1958). “The Existential Analysis School of Thought.” R.May, E. Angel, and H. F. Ellenberger (eds.), Existence: A New Dimension in Psychology and Psychiatry, pp. 191-213. New York: Basic Books.

Fernandez, A. V. (2015). “Contaminating the Transcendental: Toward a Phenomenological Naturalism.” Journal of Speculative Philosophy 29(3): 291-301.

—. (2017). “The Subject Matter of Phenomenological Research: Existentials, Modes, and Prejudices." Synthese 194(9): 3543-62.

—. (2018). "Beyond the Ontological Difference: Heidegger, Binswanger, and the Future of Existential Analysis.” In K. Aho (ed.), Existential Medicine: Essays on Health and Illness, pp. 27-42. Lanham: Rowman \& Littlefield International.

Fernandez, A. V., \& Stanghellini, G. (forthcoming). "Comprehending the Whole Person: On 
Expanding Jaspers' Notion of Empathy.” In A. L. Mishara, P. Corlett, P. Fletcher, A. Kranjec, and M. A. Schwartz (eds.), Phenomenological Neuropsychiatry: How Patient Experience Bridges Clinic with Clinical Neuroscience. New York: Springer.

Fernandez, A. V., \& Wieten, S. (2015). "Values-based Practice and Phenomenological Psychopathology: Implications of Existential Changes in Depression.” Journal of Evaluation in Clinical Practice, 21(3): 508-513.

Fuchs, T. (2001). "Melancholia as a desynchronization: towards a psychopathology of interpersonal time.” Psychopathology, 34(4): 179-186.

—. (2013). "Depression, Intercorporeality, and Interaffectivity." Journal of Consciousness Studies 20(7-8): 219-238.

Heidegger, M. (1962). Being and Time, trans. J. Macquarrie and E. Robinson. New York: Harper Perennial Modern Classics.

—. (2001). The Fundamental Concepts of Metaphysics: World, Finitude, Solitude, trans.

W. McNeill and N. Walker. Bloomington: Indiana University Press.

—. (2008). Phenomenological Interpretations of Aristotle: Initiation into

Phenomenological Research, trans. R. Rojcewicz. Bloomington: Indiana University Press.

Jaspers, K. (1968). “The phenomenological approach in psychopathology,” trans. J. N.

Curran. British Journal of Psychiatry 114: 1313-1223.

—. (1997). General Psychopathology, trans. J. Hoenig and M. W. Hamilton. Baltimore: Johns Hopkins University Press.

Køster, A. (forthcoming). ’Lidelsen i Tabet: Fænomenologiske Betragtninger Over Tabserfaringens Affektive Dybde.” Psyke \& Logos.

_. (2017a). "Embodiment, Knowledge-Generation and Disciplinary Identity." Constructivist Foundations 13(1): 70-1. 
—_. (2017b). "Personal History, Beyond Narrative: An Embodied Perspective." Journal of Phenomenological Psychology 48(2): 163-187.

—. (2017c). "Narrative and Embodiment—a Scalar Approach." Phenomenology and the Cognitive Sciences 16(5): 893-908.

Køster, A., \& Winther-Lindqvist, D. A. (2018). "Personal history and historical selfhood: a phenomenological perspective.” In A. Rosa and J. Valsiner (eds.), Cambridge Handbook of Socio-cultural Psychology. Cambridge: Cambridge University Press.

Luft, S., \& Overgaard, S. (2011). “Introduction.” S. Luft \& S. Overgaard (eds.), The Routledge Companion to Phenomenology, pp. 1-14. Hoboken: Routledge.

Parnas, J., \& Zahavi, D. (2002). "The role of phenomenology in psychiatric diagnosis and classification.” In M. Maj, W. Gaebel, J. J. López-Ibor, \& N. Sartorius (eds.), Psychiatric diagnosis and classification, pp. 137-62. New York: John Wiley \& Sons.

Ratcliffe, M. (2008). Feelings of Being: Phenomenology, Psychiatry and the Sense of Reality. Oxford: Oxford University Press.

—. (2009). "Existential Feeling and Psychopathology." Philosophy, Psychiatry, \& Psychology 16(2): 179-194.

—. (2013). "Why mood matters." In M. Wrathall (ed.), The Cambridge Companion to Heidegger's Being and Time, pp. 157-76. New York: Cambridge University Press. Smith, D. W. (2013). “Phenomenology.” In E. N. Zalta (ed.), The Stanford Encyclopedia of Philosophy, Winter 2013.

Zahavi, D. (2012). “Introduction.” In D. Zahavi (ed.), The Oxford Handbook of Contemporary Phenomenology, pp. 1-4. Oxford: Oxford University Press. 